\title{
Finding Cultural Lessons in an Unfamiliar Society: An Analysis of Japanese Books about the Amish
}

\author{
Tomomi Naka
}

\begin{abstract}
This article examines the ways in which Amish life and society are discussed in Japanese books. The Amish are a religious and cultural minority group living mainly in the United States and Canada. Most people in Japan have little or no historical and cultural ties to them. However, many Japanese books have been written about the Amish. An examination of these books indicates that in comparison with English scholarly books about the Amish, Japanese books discuss this group's cultural and social context more explicitly. This article argues that through such discussions, Japanese books not only explain that Amish society and community life are different from that of Japan's, but also offer useful insights for Japanese readers.
\end{abstract}

Index Terms-Amish, community life, Japan, representation.

\section{INTRODUCTION}

Historically and especially in contemporary times, curiosity about other cultures exists around the world. Although this interest can inspire exploration of the diversity of cultures and societies, scholars have become increasingly aware of the complex social and political factors underlying these gazes toward other cultures [1-3]. In particular, the writings about other cultures by anthropologists and other scholars have been critically reviewed as they frequently become an important source of information on these cultures. In accordance with this trend, the present article explores how the Amish, a religious minority group living mainly in the United States and Canada, are represented in Japanese books.

Several scholars have noted Japanese interest in the Amish $[4,5]$, although there are many differences between the Japanese and the Amish. Because only 1.0\% of Japanese are Christians [6], many Japanese do not have much familiarity with Christianity, on which the Amish faith and society are based. In addition, because the Amish seldom travel outside the American continent, the wide geographic separation makes it difficult for many Japanese to have opportunities to see the Amish and their culture in person. Despite this considerable cultural, religious, and geographic distance, books and other items describing the Amish do exist in Japan.

By closely examining books about the Amish published in Japan, this article considers how those books describe the Amish to Japanese readers. In contrast with books written in English, Japanese books are organized to make readers aware of the social and cultural context of Amish life. I argue that through these discussions, Japanese writers are encouraging their readers to reflect on their own society and its cultural values by thinking about Amish society. I suggest that this

Manuscript received August 22, 2016; revised December 12, 2016.

T. Naka is with the Department of Regional Culture, Tottori University, Japan (e-mail: nakatomo@rs.tottori-u.ac.jp). reflective aspect is an important characteristic of Japanese books about the Amish and illuminates a way in which studies of the Amish can be influential, even in countries with limited direct connections to them.

\section{THE AMISH}

The Amish are a Christian group, most of whose members live in the United States and Canada. As with some related Christian groups, such as the Hutterites and Mennonites, the historical and religious roots of the Amish can be traced back to the Anabaptist movement that began in 1525 in Europe. Dissatisfied with the religious practices prevalent at that time, the early Anabaptist leaders baptized each other to form their own religious group. They were critical of other Christians' practice of infant baptism and other churches' close relationships with the state [7].

Later, several subgroups developed within the Anabaptists. In 1693, under the leadership of Jakob Ammann, the group, now known as the Amish separated from Mennonites and other Anabaptists. Like other Anabaptists, the Amish were widely persecuted in Europe because of their religious convictions, and they migrated to North America, primarily in the $18^{\text {th }}$ and $19^{\text {th }}$ centuries, in search of religious freedom. According to a recent work by Donald B. Kraybill, the current estimated Amish population (including unbaptized children) in the United States and Canada is about 233,000 [8].

One characteristic of the Amish communities is their limited use of cars and electric devices. Based on their religion, the Amish emphasize mutual support among believers and separation from the values and practices that contradict and undermine their religious views. To reduce their reliance on systems outside their control, Amish communities avoid or limit certain activities, such as owning cars and using electricity from public utilities. The specific interpretation and application of these religious principles, however, vary among Amish communities [9]. Indeed, there are separate subgroups within the Amish. The Old Order Amish group does not allow its members to own cars and restricts the use of electricity and telephones in their daily lives, particularly inside their houses. Other Amish groups, in contrast, have fewer restrictions on modern devices [9].

\section{WRITINGS ABOUT THE AMISH IN ENGLISH}

Although this article focuses on Japanese books about the Amish, a general overview of how the Amish society has been depicted in English will be useful for comparative purposes. Though there are numerous religious and cultural minorities in the United States and Canada, the Amish have been 
featured in publications and other media. For instance, there exist many romance novels and reality TV programs on the Amish, such as The Shunning and Amish Mafia. There are various explanations for this interest in Amish culture, but the nostalgic and idealized images often associated with the Amish life are likely a contributing factor. These descriptions often add fictional elements, but they describe some aspects and challenges of the people raised in Amish communities [10].

Among the many available works on the topic, books written by scholars provide more thorough and comprehensive information about Amish society. Indeed, popular descriptions of the Amish often refer to these books as sources [10]. Although some of these works are in other languages, most have been written in English - understandably, since the Amish reside primarily in the United States and Canada and the scholars who have built long-term relationships with the Amish tend to live near them. Providing a comprehensive review of scholarly works on the Amish is beyond the scope of this article, but two important viewpoints appear in their writings.

One group of writings emphasizes values and principles by which the Amish communities and their responses to modern culture can be understood. As exemplified by the work of John Hostetler, a prominent figure in Amish studies, these writings often use the "folk society" model, originally proposed by Robert Redfield [11], to understand Amish society. Hostetler has further developed this concept, contending that a folk society can be characterized as an isolated, homogeneous community in which oral and face-to-face communications are highly valued [12]. Using this concept, Hostetler and others [12-15] claim that Amish society is a folk society in the sense that it values slow changes and traditional ways of living. These writings discuss how the Amish have responded to changes in the broader community while adhering to their traditions.

A second group of writings, including those by Donald Kraybill, another leading scholar in Amish studies, explores Amish society in relation to various features of modernity. Drawing on Peter Berger's work [16], Marc Olshan characterizes modernity as a situation in which "what previously was experienced as a fate now becomes an arena of choices" [17]. From this perspective, Olshan depicts the Amish are "a modern people" who try to selectively accommodate changes imposed by modernity [17]. Rather than viewing Amish responses to socioeconomic and technological changes as a preference for the old and traditional, these scholars claim that the Amish make conscious choices about what changes they accept while still maintaining their religious values and communities [17-19]. In the sense that the Amish make their own decisions, then, they are representative of modernity, but their choices embody a continuing struggle against the technological and social forms of modernity that could potentially undermine their communities.

Of course, not all scholarly works about the Amish neatly fit into these two frameworks, and there are some overlapping elements between the two. However, these are influential perspectives about Amish society. Both emphasize that the Amish and their practices are not just something peculiar and strange, and they highlight the organizing principles and values present in the Amish community. The differences between them lie in their interpretations of how the Amish view change. According to the first group, change is seen as something undesirable and, if possible, to be avoided in order to maintain traditions. In contrast, the second group sees change as an inevitable part of negotiating one's relationship with the modern society.

Regardless of their interpretive differences, both groups of scholars believe that studying the Amish has broader significance. They explain Amish society in such a way as to illuminate general lessons applicable to many cultures about preserving traditions and negotiating the challenges posed by modernity. In comparison, they are less explicit about the social and cultural contexts within which the Amish communities developed. For example, they do not present detailed examinations of how American and Canadian cultures may also have shaped the development of the Amish way of life. Similarly, schisms and the development of subgroups among the Amish have often played a role in shaping their and other groups' specific behaviors, but they have become just a part of the background rather than being discussed in detail. This is not necessarily so in Japanese writings on the Amish.

\section{WRITINGS ABOUT THE AMISH IN JAPANESE}

\section{A. Overall Trends}

Many forms of discussions and explanations about Amish society can be found in Japan, such as in newspapers and websites. However, this article specifically focuses on books because they, including both older and relatively new ones, are readily available to general readers. In addition, the focus on books allows a comparative analysis with books produced in English. Because of my selected focus here, this section presents only a brief description of wider trends in Japanese writing on the Amish, including newspaper and journal articles. For a more detailed analysis, please refer to another article [20].

As a general trend, writings about the Amish in Japan began to appear in the late 1980s. However, a few publications appeared before that date. Nobuo Sakai's books about the Amish, published in the mid-1970s [21, 22], are generally considered the earliest in-depth Japanese analysis of Amish society [23, 24]. According to Kraybill, the earliest known newspaper article on the Amish in Japanese appeared around 1972 in the Japan Times, an English-language newspaper, discussing a U.S. federal court decision on Amish education [23].

Beginning with these early publications and through the 1990s, Amish-themed articles and books appeared with increasing frequency. To examine the general tendency of the amount of publication activity in Japan, I compiled the number of publications on the Amish from two databases as a sample. For newspaper articles, I used the Kikuzo II Bijuaru, a database of Asahi Shimbun, a major Japanese national newspaper. For books and journal articles, I used the Japanese National Diet Library database, which stores data on all popular and scholarly books and articles. As Fig. 1 suggests, 
although there has been no rapid increase, there are usually at least a few publications a year, in the form of either articles or books.

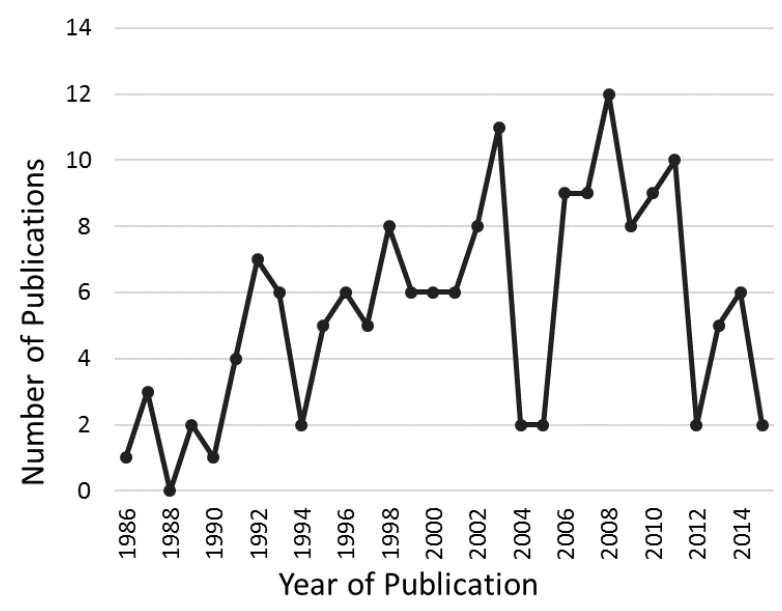

Fig. 1. Japanese Publications about the Amish since 1986.

The increased interest in the Amish during the 1990s may indicate some relationship with the general social situation in Japan at that time. After its rapid economic growth in the 1980s, Japan began to experience serious economic decline in the 1990s. Also in the 1980s, Japanese people became increasingly interested in traveling abroad. Japan's international tourism industry greatly expanded, providing new opportunities to those who had never been able to travel abroad before. A proliferation of guidebooks and television programs provided information about other cultures [25]. In this context, writings about Amish cultures were interesting and informative for many readers; moreover, considering the Amish lifestyle may have been of greater relevance to people facing times of difficult economic and social change.

\section{B. Trends in Books about the Amish}

A keyword search of the National Diet Library database found 34 books about the Amish in Japan. According to this resource, the oldest one was published in 1965. Because the word Amish is spelled in several different ways in Japanese, some books about the Amish, including those by Sakai, are not included in these results. Nevertheless, these exceptions are few, and searching by the most common Japanese spelling of the word yields a reasonable representation of books in Japan about the Amish.

Some of the general characteristics of the book market in Japan are reflected in books about the Amish. Many foreign books are translated and published in Japan, including books about the Amish. Among the 34 books found in the National Diet Library search, 13 are translations. There is not a strong division between academic and popular books in Japan. Amish books also demonstrate this tendency, although some books are targeted more at specialized readers.

Fig. 2 shows the number of books about the Amish published each year in Japan since 1986. After 1990, generally one or two books were published in most years. In 2008, five books were published, but the reason for this spike is not clear.

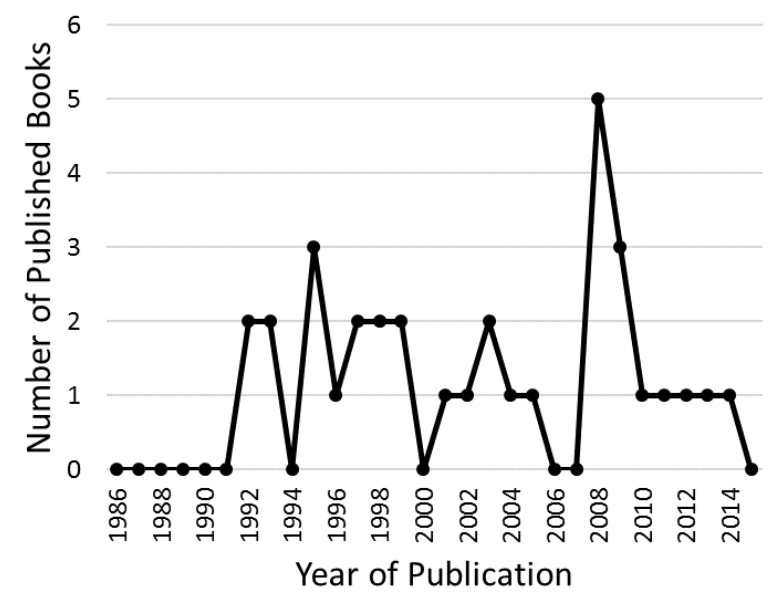

Fig. 2. Japanese Books about the Amish since 1986.

Many of these books provide general introductions to Amish society, as indicated in Table I. Five books focus on criminal and legal incidents. Food is another popular category, but even these books devote many pages to introducing readers to Amish society. For instance, unlike ordinary recipe books, most of these works include discussions of Amish daily life and communities and how they are organized according to their specific cultural and religious values. Because of this, the following analysis pays attention to the ways in which the authors explain and discuss the Amish and their society in general.

TABLE I: JAPANESE BOOKS ABOUT THE AMISH BY TOPIC CATEGORY

\begin{tabular}{ll}
\hline \hline Topics & Number of Books \\
\hline Art/Quilts & 1 \\
Business & 0 \\
Criminal and Legal Incidents & 5 \\
Education & 1 \\
Food & 5 \\
Language & 0 \\
Literature & 1 \\
Peace and Peace Movement & 0 \\
Physical and Mental Health & 1 \\
Religion & 1 \\
Society (General Introduction) & 15 \\
Technology and Environment & 1 \\
Welfare/Community/Family & 0 \\
Other Topics & 3 \\
\hline \hline
\end{tabular}

\section{Discussions of the Amish}

One reason why Japanese books provide substantial information on Amish society, regardless of the main subject of the book, is related to the fact that the Amish are historically and culturally unfamiliar to most Japanese readers. To some extent, American and Canadian books also have to explain the peculiarity of the Amish way of life, but their readers' familiarity with general American and Canadian cultural and social contexts makes the distinctive aspects of Amish life more obvious. In contrast, Japanese readers may not recognize those distinctive aspects as readily when interpreting Amish life against the backdrop of other people, such as large numbers of residents in Asian nations, who also live without cars and electricity. For this reason, Japanese books make a greater effort to explain how the Amish way of life differs from that of typical Americans and Canadians and 
also stress that Amish life, while it may seem strange, is based on certain principles. In these discussions, important characteristics of Japanese narratives appear.

An examination of how the Japanese books describe Amish society indicates that they place a strong emphasis on the values that the readers can discover through learning about the Amish. To some extent, this tendency is understandable. After all, if there is nothing interesting or intellectually stimulating in some topic, few people will want to read a book about it. However, Japanese books not only present the Amish as interesting people but also suggest the authors' desire to convey that readers can learn something more by studying the Amish.

For example, after explaining that the Amish are not a stubborn group of people who reject technological innovations, Chiyoshi Sugawara expresses his hope that an increasing number of people can be reminded of what are the most valuable things in their lives - things often forgotten in contemporary society [26]. Similar sentiments can be found in Satoshi Ikeda's book. He seeks to convince readers that the Amish are not an outdated group of people, but that they make reasonable compromises in ways that do not shake their basic value systems. At the same time, he also maintains his conviction that Amish communities and people demonstrate important human values [27]. While some works are more explicit than others in this regard, Japanese writing about the Amish commonly suggests there are some valuable lessons to discover through learning about the Amish.

As these examples from Sugawara and Ikeda indicate, many Japanese authors leave open the question of exactly what those lessons and values are. The ways in which they describe Amish society, however, provide some hints. Books published before 2000 tend to describe Amish communities as ideal societies with few if any problems. For example, Ikeda writes that Amish society does not experience social or psychological problems. He adds that the principle of competition does not apply to their society and that there are no gender-based differences [28]. Similarly, Sugawara writes that the problems of loneliness, aging society, and collapse of families are not observed in Amish communities [29]. While these statements may serve to emphasize potential insights and lessons for readers, they appear rather simplistic.

More recent publications indicate that views of the Amish in Japanese books have changed over time. In comparison to earlier books, later ones mention challenges and problems in Amish communities. For instance, Mami Okawara discusses several legal cases in which Amish people have been involved She includes cases in which Amish have been the accused as well, such as Amish youth arrested for drunken buggy driving [30]. Other books explore additional challenges within Amish communities, such as how to respond to increased difficulties in sustaining their farming livelihoods or the spread of mobile media devices (which are less difficult to control). These depictions present much more nuanced views of Amish life rather than simply idealizing it.

Such changes, from relatively simplistic to more complicated views of Amish society, can also be seen in English books about the Amish. Earlier books, such as The Amish Society by Hostetler, described the Amish as a coherent and well-organized society that operates based on clear value systems and with few difficulties [31]. This emphasis may reflect the fact that dispelling the image of the Amish as a strange group and introducing Amish core values was an important focus at that time. Later works, such as The Amish Struggle with Modernity by Kraybill and Olshan, provide more complex views, discussing compromises and challenges faced by the Amish communities in response to the changing social contexts [32]. Through such descriptions, more recent books suggest that the Amish present an interesting case of considering how to respond to modern society.

Both Japanese and English writings about the Amish, then, have gradually presented more complex social descriptions. In so doing, they also guide readers to find some applications from Amish life to their own lives. These books suggest that Amish communities have difficulties, just like the rest of us, but that they try to respond to these challenges through distinctive forms of communal efforts. Despite this similarity, however, there remains an important difference between the two sets of publications. Japanese books are much more explicit about the social and cultural contexts in which the Amish live, while also emphasizing the relevance of the Amish society to readers' contemporary lives.

Okawara's book, mentioned earlier, provides an illustrative example. Carefully examining the Amish involvement in court cases, she argues that the Amish can be best viewed as a cultural minority in the American context. After discussing how American society values religious freedom and cultural and social distinctiveness, she claims that this context is essential in enabling Amish society to thrive. She further asserts that examining Amish society can help us develop a better understanding of contemporary American society as well as offering insights relevant to the Japanese people and their society. She suggests, for example, that studying the Amish can inform Japanese considerations of how to develop agriculturally oriented communities [33]. While emphasizing the differences between the cultures, Okawara maintains that understanding the Amish can have direct relevance for people in Japan.

Several other authors also point out the social contexts surrounding the Amish and how they differ from those in Japan. For example, Sugawara claims the existence of a general sympathy toward the Amish in the United States and says that this must have contributed to the group's survival and to the development of Amish society [34]. Like Okawara, Sugawara also relates the Amish case to Japanese society, noting that an examination of Amish life reminds people of their uncritical views of material abundance [35].

Other books focus more on Amish society itself, discussing the differences between it and seemingly similar behaviors and situations in Japan. Noriko Kurihara and Asami Hasegawa provide one such example. As a journalist and photographer, respectively, they found it difficult to get to know people in Amish communities. Even when they were able to talk to a few people, they were constantly reminded not to use names or to take photos. They write that these requests proceed from the Amish's concern about how their community will view them. While noticing the power of the Amish community over individual behavior, Kurihara and Hasegawa also describe how the Amish community provides 
support when members are in need. They then compare this situation to that of Japan and invite readers to examine their own society. They observe that Japanese people also often worry about what others will say, but they ask whether Japanese communities provide comparable care and support to their members in need [36]. The implication is that the strong communal support system present among the Amish does not exist in Japan. Ikeda makes a similar reference to Japanese culture, noting that the Amish community members have a clear sense of purpose in their lives, unlike many Japanese [37]. Through these descriptions, both books urge readers to reconsider their views of their own life and society.

In comparison with the works by Okawara, these books pay attention primarily to the differences between Amish and Japanese society. Their gaze toward cultural and social contexts is limited in this perspective. However, like Okawara these authors also suggest that looking at the Amish can provide a critical but informative perspective on Japanese society. By pointing out the differences between what at first may seem to be similar practices, these books present their Amish representations as a reflective tool, inviting Japanese readers to ponder possible meanings for their own society and for life in Japan.

As noted above, in the books published in English, the emphasis on specific contexts of the Amish and the surroundings is not as apparent as in Japanese publications. Whether the English-language books apply Hostetler's folk society model or the framework of negotiation with modernity, they tend to treat specific North American and Amish cultural and religious contexts as background information when they discuss the Amish. As such, English books make few comments that ask readers to consider their own society. In contrast, by discussing differences in those contexts, Japanese books present their Amish representations as a reflective tool for the Japanese readers.

\section{CONCLUSION}

Despite the cultural, social, and geographic distance between the Amish and Japanese society, many books about the Amish have been published in Japan. The topics of these works are diverse, but they commonly include general discussions of Amish society. An analysis of these discussions suggests that they highlight ways in which Amish life is relevant to Japanese readers, despite the cultural and social differences between Amish and Japanese ways.

The discussions of these differences do not guide readers toward easy solutions or direct imitation of the Amish case. Instead, readers are encouraged to consider what lessons and insights can be derived from the Amish despite the existence of profound cultural differences. In so doing, Japanese books also make their readers more cognizant of their own cultural and social distance from Amish society.

Although this article has examined only Japanese publications about the Amish, critical, reflective perspectives can be a significant aspect of any outside study of the Amish. For those who have few cultural and social ties to the Amish, the particularity of Amish communities is more obvious. Precisely because of these differences, scholarship on the
Amish can invite readers to find insights and solutions relevant to their own situations.

Writing about other cultures is not an easy task, and decisions on how to represent such cultures can have political and social consequences. Readers and writers should pay careful and critical attention to these writings, but they should also be alert to the broad significance of understanding other cultures, which is clearly illuminated by the approach and implications contained in Japanese works on the Amish.

\section{REFERENCES}

[1] J. Clifford, "Introduction: Partial truths," in Writing Culture: The Poetics and Politics of Ethnography, J. Clifford and G. Marcus, Ed. Berkeley: University of California Press, 1986, pp. 1-26.

[2] J. Clifford, The Predicament of Culture: Twentieth-Century Ethnography, Literature, and Art, Cambridge, MA: Harvard University Press, 1988

[3] E. W. Said, Orientalism, New York: Penguin Classics, 2003.

[4] M. Okawara, The Amish in the Court, Tokyo: Akashi Shoten, 2014, pp. 24-36.

[5] D. B. Kraybill, The Amish of Lancaster Country, (T. Sugihara \& C. Oyabu, Trans.), Tokyo: Ronsosha 2009, pp. 3-4.

[6] Shukyo Nenkan Heisei 27 Nenndo (Year book of Religions 2015) [Online]. Bunka Cho. Available: http://www.bunka.go.jp/tokei_hakusho_shuppan/hakusho_nenjihoko kusho/shukyo_nenkan/pdf/h27nenkan.pdf

[7] D. B. Kraybill, Concise Encyclopedia of Amish, Brethren, Hutterites and Mennonites, Baltimore, MD: The Johns Hopkins University Press, 2010, pp. 7-10.

[8] D. B. Kraybill, Concise Encyclopedia of Amish, Brethren, Hutterites and Mennonites, Baltimore, MD: The Johns Hopkins University Press, 2010, p. 8

[9] D. B. Kraybill and C. F. Bowman, On the Backroad to Heaven: Old Order Hutterites, Mennonites, Amish, and Brethren, Baltimore, MD: The Johns Hopkins University Press, 2001.

[10] V. Weaver-Zercher, Thrill of the Chaste: The Allure of Amish Romance Novels, Baltimore, MD: The Johns Hopkins University Press, 2013.

[11] R. Redfield, "The folk society," American Journal of Sociology, vol. 52, pp. 293-308, January 1947

[12] J. A. Hostetler, Amish Society, 4th ed. Baltimore, MD: The Johns Hopkins University Press, 1993.

[13] H. E. Cross, "Population studies and the Old Order Amish," Nature, vol. 262, pp. 17-20, July 1, 1976.

[14] H. M. Hoover and K. H. Hoover, Concepts and Methodologies in the Family: An Instructor's Resource Handbook, Boston: Allyn and Bacon, 1979.

[15] W. M. Kephart and W. W. Zeller, Extraordinary Groups, New York: St. Martin's Press, 1991.

[16] P. L. Berger, Pyramids of Sacrifice, New York: Basic Books, 1974, p. 21.

[17] M. A. Olshan, "Modernity, the folk society, and the Old Order Amish," in The Amish Struggle with Modernity, D. B. Kraybill and M. A. Olshan Eds. Hanover, NH: University Press of New England, 1994, p 188.

[18] D. B. Kraybill and C. F. Bowman, On the Backroad to Heaven: Old Order Hutterites, Mennonites, Amish, and Brethren, Baltimore, MD: The Johns Hopkins University Press, 2001.

[19] D. B. Kraybill and S. M. Nolt, Amish Enterprise: From Plows to Profits, Baltimore MD: The Johns Hopkins University Press, 1995.

[20] T. Naka, "Representations of the Amish in Japan," presented at the Continuity and Change: 50 Years of Amish Society, Elizabethtown, PA, June 9-11, 2016.

[21] S. Nobuo, ACultures and Society of the Amish, Tokyo: Yorudansha, 1973.

[22] S. Nobuo, Studies about the Amish, Tokyo: Kyobun kan, 1977.

[23] D. B. Kraybill, The Amish of Lancaster Country, (T. Sugihara \& C. Oyabu, Trans.). Tokyo: Ronsosha, 2009, p.3.

[24] M. Okawara, M. Hotei no naka no amisshu [The Amish in the Court], Tokyo: Akashishoten, 2014, p. 35.

[25] N. Furuichi, Welcome to the Hopeful Refugees: Peace Boat and the Illusion of Community of Approval, Tokyo: Kobunsha, 2010.

[26] C. Sugawara, Dinner Tables of the Amish, Tokyo: Maruzen Books, 1999, pp. iv-vii. 
[27] S. Ikeda, The Amish: Culture of Contentment and Simplicity, Tokyo: Nigensha, 2009, pp. 9-10.

[28] S. Ikeda, The Amish: Culture of Obedience and Simplicity, Tokyo: Saimarushuppan, 1995, p. 5.

[29] C. Sugawara, Dinner Tables of the Amish, Tokyo: Maruzen Books, 1999, pp. iv-vii.

[30] M. M. Okawara, The Amish in the Court, Tokyo: Akashishoten, 2014

[31] J. A. Hostetler, Amish Society, 4th ed. Baltimore, MD: The Johns Hopkins University Press, 1993.

[32] D. B. Kraybill, "The Amish encounter with modernity," in The Amish Struggle with Modernity, D. B. Kraybill and M. A. Olshan Eds. Hanover, NH: University Press of New England, 1994, pp. 21-34.

[33] M. M. Okawara, The Amish in the Court, Tokyo: Akashishoten, 2014, p. 36.

[34] C. Sugawara, The Amish Life and Quilts, Tokyo: Maruzen Books, 2001, p. ix.

[35] C. Sugawara, The Amish Life and Quilts, Tokyo: Maruzen Books, 2001, p. iv.

[36] N. Kurihara and A. Hasegawa, Plain People: The World of the Amish, Toyo: Aiikusha, 1998, pp. 150-151.
[37] S. Ikeda, The Amish: Culture of Obedience and Simplicity, Tokyo: Saimarushuppan 1995, p. 3.

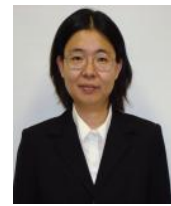

Tomomi Naka is an associate professor in the Department of Regional Culture at Tottori University, Japan. She received a $\mathrm{PhD}$ in anthropology at the University of Iowa, Iowa City, USA, in 2009. She has been researching the relationships between religion and economic activities, representations of cultural and religious minorities, and short- and long-term cross-cultural experiences. Before returning to Japan, she worked in the United States and Bangladesh as a university and college instructor. For two decades, she has been studying the Amish and Mennonites in the United States, and she has published several articles in English and Japanese on this topic.

Dr. Naka is a member of the American Anthropological Association and the Japanese Society of Cultural Anthropology. She has received many awards and fellowships, including a graduate summer fellowship at the Young Center for Anabaptist and Pietist Studies at Elizabethtown College, Elizabethtown, Pennsylvania, USA. 